Open Access

\title{
The short- and long-term effects of a computerized reading training program on reading self-concept in second and third grade readers
}

Ronen Kasperski ${ }^{2,3}$, Michal Shany ${ }^{1}$, Tal Erez-Hod ${ }^{1}$ and Tami Katzir ${ }^{1 *}$

\footnotetext{
* Correspondence: katzirta@gmail. com

${ }^{1}$ Department of Learning Disabilities and Special Education, University of Haifa, 31905 Mount Carmel, Israel Full list of author information is available at the end of the article
}

\begin{abstract}
While computerized reading programs were found to enhance reading skills, less is known about their influence on reading self-concept (RSC). The current study aimed to examine short- and long-term effects of two versions of a computerized reading acceleration program (RAP) on reading skills and reading self-concept. One hundred thirty Hebrew-speaking second to third grade students completed 6 months of training with a computerized reading program. The results revealed significant shortterm effects in both conditions for RSC. Furthermore, at the posttest, RSC of struggling readers was significantly higher in comparison to the RSC of second to third grade struggling readers from an age-matched normative sample that did not receive the reading training. Importantly, these gains remained evident 6 months after training was completed.
\end{abstract}

Keywords: Reading intervention, Reading self-concept, RAN, Reading rate, Reading fluency

\section{Introduction}

During the past two decades, there has been a shift in research and in definitions toward a more multi-dimensional perspective on reading, which includes the contribution of reader's characteristics and environmental factors that are thought to go beyond cognitive and linguistic processes (Bandura, 1986; Guthrie \& Wigfield, 1999; Schunk, 1987; Sweet \& Snow, 2002; Zimmerman, 2002). Situated within the realms of motivation is reading self-concept (RSC), a motivation-related construct found to facilitate reading achievements. Conradi, Jang, and McKenna (2014) defined RSC as "An individual's overall self-perception as a reader, including one's sense of competence and the role ascribed to reading as a part of one's personal identity" (p. 154). The significant contribution of RSC to other aspects of reading was established in previous studies, even after controlling for underlying cognitive and linguistic processes (Conlon, Zimmer-Gembeck, Creed, \& Tucker, 2006; Katzir, Lesaux, \& Kim, 2009).

Numerous studies have shown that struggling readers tend to fall further behind as they progress through school if their core deficits are not properly treated (Hurry \& Sylva, 2007) and that failure to learn to read can have serious long-term consequences

(C) The Author(s). 2019 Open Access This article is distributed under the terms of the Creative Commons Attribution 4.0 International License (http://creativecommons.org/licenses/by/4.0/), which permits unrestricted use, distribution, and reproduction in any medium, provided you give appropriate credit to the original author(s) and the source, provide a link to the Creative Commons license, and indicate if changes were made. 
for literacy development and self-concept (Chapman \& Tunmer, 2003). Meanwhile, questions about the ability of reading interventions and reading training to change how struggling readers perceive their reading abilities have not received much attention in reading research. Such questions re-examine the interplay between cognitive and emotional factors in reading and essentially test whether cognition-based reading interventions and training can affect related emotional factors.

According to Bandura (1993), learning environments that highlight personal progress and de-emphasize competitive social comparison are well suited for building one's sense of efficacy. Following this approach, computerized reading training programs, which provide a personalized learning environment, matching the reading profile of each participant, may be beneficial not only for children's progress in reading but also for their RSC. Thus, the current study aimed to explore whether an in-class computerized reading program can bring about short- and long-term changes in RSC.

Self-perceptions are products of both cognitive and social-emotional processing, as individuals assign meaning to ongoing patterns of success or failure in particular situations. Bandura (1991) argued that previous experiences are used as a reference when judging self-performance. The cognitive processes by which individuals evaluate their ability to cope with reading demands are sometimes accompanied by less desirable emotional manifestations, such as anxiety, in the case of persistent academic deficits (Heath \& Ross, 2000; Klassen, Tze, \& Hannock, 2011). Marsh (1986) suggested an internal/external frame of reference model (I/E model) for the formation of academic self-concept. According to this model, students compare their level of academic ability using two different but connected frames of reference: internal and external comparison processes. In the field of reading, internal appraisal can be associated with pleasure from reading books. It may be influenced by the home literacy environment and by specific experiences. External points of reference can be related to feedback from teachers and comparisons to peers, with respect to the performance of reading tasks. Indeed, studies have shown that students form beliefs regarding the quality of their reading on the basis of their various former reading experiences. These self-beliefs are termed "reading self-concept" (RSC, Chapman \& Tunmer, 1995, 2003). The term RSC was developed into a scale, in order to evaluate children's self-perceptions of their strengths, difficulties, and feelings about reading. Consistent findings show that RSC is related to word reading and reading comprehension even when controlling for underlying cognitive and linguistic processes (Conlon, Zimmer-Gembeck, Creed, \& Tucker, 2006; Katzir, Lesaux, \& Kim, 2009).

Chapman and Tunmer $(1995,1997)$ argued that RSC is influenced by reading experiences and achievements and becomes more strongly linked to reading achievement as children progress in school. Accordingly, in order to form a stable RSC, readers must first demonstrate consistent patterns of proficiency or difficulty in reading, which normally take a few years to develop. Cultivating a positive RSC in a classroom setting, that consists of students with heterogenous reading profiles, is not a simple task. In this context, technology can help teachers adjust reading materials according to the reading level of each student, so that the students would experience success in reading and as a result will benefit in terms of RSC.

Guthrie and Klauda (2014) recently noted that only a relatively small set of studies used experimental designs to examine instructional effects on motivation or 
engagement in short-term conditions. As seen in Table 1, some studies (Chapman, Tunmer, \& Prochnow, 2001; Chen \& Savage, 2014; Förster \& Souvignier, 2014) have in fact shown that reading interventions may lead to undesirable effects on RSC, simply because readers are confronted with their reading difficulties. Chapman, Tunmer, and Prochnow (2001) found a steady decline in the RSC of struggling readers who successfully completed a reading recovery (RR) program. This decline occurred while they were participating in the RR program, continued immediately following the RR program, and was found at follow-up as well (middle and end of the third year). Förster and Souvignier (2014) found negative effects of feedback and reflections on the development of RSC among fourth grade readers. Although the authors aimed to enhance student achievement and RSC by providing immediate performance feedback on curriculum-based reading assignments, the opposite occurred. In explaining this

Table 1 Studies included in the review regarding the effects of reading intervention on reading self-concept (RSC)

\begin{tabular}{|c|c|c|c|c|}
\hline Authors & Title & Participates & Intervention type & Results \\
\hline $\begin{array}{l}\text { Bates, D'Agostino, } \\
\text { Gambrell, and Xu } \\
\text { (2016) }\end{array}$ & $\begin{array}{l}\text { Reading recovery: } \\
\text { exploring the effects on } \\
\text { first graders' reading } \\
\text { motivation and } \\
\text { achievement }\end{array}$ & $\begin{array}{l}\text { First grade } \\
\text { children }\end{array}$ & Phonological & $\begin{array}{l}\text { Increase in reading } \\
\text { motivation }\end{array}$ \\
\hline $\begin{array}{l}\text { Chapman, Tunmer, } \\
\text { and Prochnow } \\
\text { (2001) }\end{array}$ & $\begin{array}{l}\text { Does success in the } \\
\text { reading recovery } \\
\text { program depend on } \\
\text { developing proficiency in } \\
\text { phonological-processing } \\
\text { skills? A longitudinal } \\
\text { study in a whole lan- } \\
\text { guage instructional } \\
\text { context }\end{array}$ & $\begin{array}{l}\text { Second grade } \\
\text { children }\end{array}$ & Phonological & $\begin{array}{l}\text { Decrease in RSC, which } \\
\text { continued at the follow- } \\
\text { up testing point as well } \\
\text { (middle and end of the } \\
\text { third year) }\end{array}$ \\
\hline $\begin{array}{l}\text { Chen and Savage } \\
\text { (2014) }\end{array}$ & $\begin{array}{l}\text { Evidence for a simplicity } \\
\text { principle: teaching } \\
\text { common complex } \\
\text { grapheme-to-phonemes } \\
\text { improves reading and } \\
\text { motivation in at-risk } \\
\text { readers }\end{array}$ & $\begin{array}{l}\text { First grade } \\
\text { and second } \\
\text { grade children }\end{array}$ & Phonological & $\begin{array}{l}\text { Increase in RSC only for } \\
\text { the second grade } \\
\text { readers. The first grade } \\
\text { readers did not improve } \\
\text { their RSC }\end{array}$ \\
\hline $\begin{array}{l}\text { Förster and } \\
\text { Souvignier (2014) }\end{array}$ & $\begin{array}{l}\text { Learning progress } \\
\text { assessment and goal } \\
\text { setting: effects on } \\
\text { reading achievement, } \\
\text { reading motivation and } \\
\text { reading self-concept }\end{array}$ & $\begin{array}{l}\text { Fourth grade } \\
\text { readers }\end{array}$ & Metacognitive & $\begin{array}{l}\text { Decrease in RSC due to } \\
\text { teachers' feedback which } \\
\text { contrasted the readers' } \\
\text { overestimation of } \\
\text { reading skills with actual } \\
\text { performance. }\end{array}$ \\
\hline $\begin{array}{l}\text { Higgins, Fitzgerald, } \\
\text { and Howard (2015) }\end{array}$ & $\begin{array}{l}\text { Literacy Lift-Off: an ex- } \\
\text { perimental evaluation of } \\
\text { a reading recovery pro- } \\
\text { gram on literacy skills } \\
\text { and reading self-concept }\end{array}$ & $\begin{array}{l}\text { First grade } \\
\text { readers }\end{array}$ & Phonological & Increase in RSC \\
\hline $\begin{array}{l}\text { Hornery, Seaton, } \\
\text { Tracey, Craven, } \\
\text { and Yeung (2014) }\end{array}$ & $\begin{array}{l}\text { Enhancing reading skills } \\
\text { and reading self-concept } \\
\text { of children with reading } \\
\text { difficulties: adopting a } \\
\text { dual approach } \\
\text { intervention }\end{array}$ & $\begin{array}{l}\text { Second to fifth } \\
\text { grade readers }\end{array}$ & Fluency & Increase in RSC \\
\hline $\begin{array}{l}\text { Law and } \\
\text { Kratochwill (1993) }\end{array}$ & $\begin{array}{l}\text { Paired reading: an } \\
\text { evaluation of a parent } \\
\text { tutorial program }\end{array}$ & $\begin{array}{l}\text { Second to fourth } \\
\text { grade readers }\end{array}$ & Fluency & $\begin{array}{l}\text { Increases in self- } \\
\text { confidence and attitude } \\
\text { toward reading }\end{array}$ \\
\hline Nes Ferrara (2005) & $\begin{array}{l}\text { Reading fluency and self- } \\
\text { efficacy: a case study }\end{array}$ & $\begin{array}{l}\text { A sixth-grade } \\
\text { struggling reader }\end{array}$ & Fluency & $\begin{array}{l}\text { Increases in RSC and self- } \\
\text { efficacy }\end{array}$ \\
\hline
\end{tabular}


discrepancy, the authors suggested that confronting students with their actual performance and asking them to reflect on it, contrasted with their tendency to overestimate their skills and led to a decrease in RSC (Förster \& Souvignier, 2014).

On the other hand, paired reading studies have reported positive short-term effects on RSC. In a single-subject case study, Nes Ferrara (2005) documented such effects following an 11-week paired reading intervention (30-40-min sessions, 5 days a week). The author showed that the achievement of daily goals in reading fluency enhanced the reader's self-concept and self-efficacy beliefs with respect to reading. A qualitative study conducted by Hornery, Seaton, Tracey, Craven, and Yeung (2014) incorporated both paired reading and RSC enhancement strategies. After 15 sessions, second to fifth grade readers reported feeling more capable of reading and having more reading skills, indicating improved RSC. In a quantitative paired reading study led by Law and Kratochwill (1993), parents reported a change in self-confidence and attitude toward reading in their children after 30 paired reading intervention sessions of 10 min each.

Studies that examined the effects of phonic-based interventions on reading motivation and RSC among first grade readers show contradictory findings. Bates, D'Agostino, Gambrell, and $\mathrm{Xu}$ (2016) showed an improvement in both reading skills and reading motivation among first grade children with reading difficulties who participated in an individual reading recovery (RR) program, as compared to a control group. Higgins, Fitzgerald, and Howard (2015) implemented a whole-class version of the RR program among first grade readers and found that their RSC improved after 8 weeks of training (five times a week). In contrast, Chen and Savage (2014) found no increase in RSC among at-risk first grade readers who received 30 sessions of phonic intervention (20 min each). Their findings showed increased RSC only in second grade readers.

The current study aimed to examine the short- and long-term effects of a computerized reading acceleration program (RAP) on reading skills and RSC. The reading acceleration program (RAP, Breznitz \& Bloch, 2010) was developed in order to enhance reading fluency among individuals with dyslexia and among slow readers (Berninger, Lee, Abbott, \& Breznitz, 2009; Breznitz, 1997, 2006; Breznitz \& Share, 1992; Breznitz, Shaul, Horowitz-Kraus, Sela, Nevat, \& Karni, 2013; Horowitz-Kraus, Cicchino, Amiel, Holland, \& Breznitz, 2014; Nevo, Brande, \& Shaul, 2016; Snellings, van der Leij, de Jong, \& Blok, 2009). The rationale underlying the software is that letters disappear while reading, which eliminates the option of backtracking, a function that has been found to push readers to read quicker and more accurately (Breznitz et al., 2013). When using the acceleration component, the rate of disappearance is based on an algorithm calculated according to the reader's natural reading pace. It is set to make the disappearance rate a bit faster than the natural reading pace and therefore "encourages" readers to read faster.

Improvement in reading levels following training with the RAP was found in previous studies (Berninger, Lee, Abbott, \& Breznitz, 2013; Horowitz-Kraus et al., 2014; Nevo, Brande, \& Shaul, 2016). In a study by Horowitz-Kraus et al. (2014), 89 children with dyslexia, half Hebrew speaking and half English speaking, underwent 4 weeks of reading training using the RAP software. Results showed significant improvement in reading measures, for both languages. Nagler et al. (2015) also found post-training gains in reading fluency, among German third graders, using the RAP. 
Although the software is called RAP, it also has a not-accelerated, self-paced reading option, so that the reading instructor can decide whether the software should gradually accelerate the rate of disappearance (i.e., with the acceleration component) or whether the disappearance rate should remain fixed throughout the reading sessions, according to the reader's initial reading pace (i.e., without the acceleration component). Two previous studies that compared the accelerated condition to the self-paced control condition among elementary school children (Brande, 2011; Snellings et al., 2009) found that the accelerated version of the program produced larger effects in terms of reading fluency and comprehension, compared to the self-paced control.

However, none of the above explored the potential contribution of the acceleration component to promoting RSC. This direction is worth of further examination because Kasperski, Shany, and Katzir (2016) recently found that rapid automatized naming of letters (RAN-L) and reading rate were the only significant predictors of variance in RSC among Hebrew-speaking students in second and third grade. These findings suggest that especially for young developing readers, individual differences in reading rate are highly salient factors in the self-assessment of reading competence and may act as points of reference for the social-emotional processes in which RSC is formed and shaped.

In terms of struggling readers, research demonstrates that even when they manage to compensate for poor word identification skills, their reading rate remains two to three times slower than that of their skilled reader peers, making their reading dysfluent (Jenkins, Fuchs, van den Broek, Espin, \& Deno, 2003; Torgesen et al., 2001). This dysfluency may negatively affect their motivation to read (Nathan \& Stanovich, 1991) and lead to a "Matthew effect" in reading, in which the poor readers read less than good readers. As a result, they do not improve their poor reading skills and the gap between their reading abilities and those of their peers increases (Stanovich, 2009). However, as shown in Table 1, over the past two decades, research has neglected the contribution of fluency-based programs as a means of promoting RSC.

\section{Summary and aims of the current study}

While computer-based instructional reading programs such as RAP were found to enhance reading skills among children with low reading skills and those at risk for reading disorders, less is known about their influence on RSC. Thus, the first goal of this study was to examine whether a computerized reading program can bring about short-term changes in RSC.

The second goal was to explore the clinical implications of reading rate on RSC, by comparing the effects of the accelerated condition, which was deliberately meant to enhance reading fluency, to the effects of the self-paced control, in terms of facilitating reading skills and RSC. That is, if reading rate predicts RSC, then accelerating the reading rate may prove to be more efficient for facilitating RSC in comparison to self-paced reading.

The third goal was to examine long-term effects on RSC over time, an aspect that has not received sufficient attention, as only one (Chapman, Tunmer, \& Prochnow, 2001) intervention study examined this issue to date. These long-term effects were measured 6 months after the training ended.

Three research questions were composed: 
1. Can a computerized reading training program facilitate RSC?

2. Will the accelerated version of the RAP lead to greater RSC gains than the selfpaced control version?

3. What are the long-term effects of computerized reading training in terms of sustaining RSC gains?

\section{Method}

\section{Participants}

The sample was comprised of 130 Hebrew-speaking students (all native speakers), 69 (53.1\%) boys, and 61 (46.9\%) girls, in the second and third grade (56 and 74, respectively). Age ranged from 6.1 to $9.05(M=7.64 ; S D=0.61)$. The sample was drawn from three diverse schools in northern Israel: 91 children from a private school and 39 children from two different public elementary schools. The analysis revealed no between-school differences in reading performance or RSC.

We acknowledge that implementation of any training program on the classroom level is subject to natural reading differences within the classroom. Thus, before beginning the training, a screening procedure for word reading level was administered. Based on the screening process, 79 children were defined as typical readers and 51 as struggling readers, meeting the following segmentation criteria: (a) 39 students who performed below the 25th percentile in terms of reading speed or reading accuracy on word identification, (b) 6 students who performed below the 35th percentile on word identification and below the 25th percentile on text reading, (c) 6 students who were identified by their teachers as struggling readers. The latter group performed below the 25th percentile on text reading but above the 35 th percentile on word identification.

The students were then randomly assigned to either the accelerated condition or the self-paced control condition. We also ensured that the training groups were balanced in terms of non-verbal and verbal abilities, in order to avoid other confounding variables that may have influenced the results.

\section{Reading training conditions}

The RAP software (Breznitz \& Bloch, 2010 Reading acceleration training program. Unpublished) was implemented as an in-class literacy instruction consisting of 28 sessions lasting $30 \mathrm{~min}$ each, over a period of 6 months (once or twice a week), under two conditions (with and without the acceleration component):

1. Accelerated condition. In this condition, the software gradually accelerates the participant's reading rate, using a letter-by-letter erasing method. The items are erased letter-by-letter at a rate of $2 \%$ faster than the reader's initial per-letter reading rate. If the participant achieves $80 \%$ accuracy by the end of a given unit, the program accelerates the letter-by-letter erasing rate by an additional $2 \%$. That is, the items are deleted $2 \%$ faster than in the previous unit.

2. Self-paced control (i.e., without the acceleration component). In the self-paced control condition, the letter-by-letter deletion rate remained fixed during the entire training period, in accordance with the initial reading rate, and there was no further acceleration of the deletion rate. 


\section{Study measures}

Ninety-three informative and narrative texts were gathered for the current study, from second and third grade textbooks. The texts were grouped into 31 units organized by themes, such as houses, factories, weather, and the environment. Each unit contained activities on the single word level and three semantically related texts comprised of four or five sentences each. The length of each sentence was from six to 16 words.

Methodologically, it is important to note that children in both the accelerated and self-paced conditions, who trained together using the RAP software, were unaware of the condition to which they were assigned. In addition, the classroom teacher and the experimenter as well were not aware of the condition to which each reader was assigned to.

\section{Reading measures}

Three reading measures were taken from the standardized Hebrew Reading and Writing Achievement Test - Alef Ad Taf (Shany, Lahman, Shalem, Bahat, \& Zieger, 2006). During administration, reading time and reading errors were documented by the experimenter. In the coding phase, accuracy index (i.e., percent of errors) and rate index (i.e., items per minute) were calculated for each task. Raw scores were then converted to standardized scores and compared to the national norms.

1. Word identification (Alef Ad Taf, Shany et al., 2006). Participants were asked to read a list of 38 single isolated pointed (i.e., with diacritics) words at their natural reading rate and as accurately as possible. All 38 words were nouns, and they differed in terms of frequency level, length, and morphological structure. The reported Cronbach's $\alpha$ for the test was .85 (Shany et al., 2006).

2. Word attack (Alef Ad Taf, Shany et al., 2006). Participants were instructed to read a list of 33 non-words at their natural reading rate and as accurately as possible. The reported Cronbach's $\alpha$ was 90 (Shany et al., 2006).

3. Oral text reading (Alef Ad Taf, Shany et al., 2006). Participants were instructed to read aloud a passage that contained 99 words with diacritics, taken from a second grade level story. Reliability for the test was measured based on correlations with accuracy and rate on parallel tests (narrative stories for different grade levels). Correlations were $r=.79$ in second grade and $r=.82$ in fourth grade for accuracy and $r=.88$ in second grade and $r=.88$ in fourth grade for rate (Shany et al., 2006).

\section{Reading comprehension}

Measures representing two levels of reading comprehension were employed, as follows:

1. Reading comprehension level 1 (Katzir, Hershko, \& Halamish, 2013). The task contained two second grade level texts that were matched in terms of difficulty and length. The length of each text ranged from 44 to 47 words. Each text was presented as a whole paragraph followed by four multiple-choice comprehension questions with four response options each. The reported Cronbach's $\alpha$ was .75 (Katzir, Hershko, \& Halamish, 2013). Cronbach's $\alpha$ in the current study was .72. 
Testing was not time-limited; it took participants approximately 10-15 min to finish the entire test.

2. Reading comprehension level 2 (Tov-li, 2000). The task contained a 105-word passage at third grade reading level and five open-ended reading comprehension questions. The questions assessed semantic understanding, comprehension of the story structure, and inference making. Texts were available to participants while they responded to the questions, such that performance was not reliant on memory skills. Testing was not time-limited; it took the subjects approximately $30 \mathrm{~min}$ to finish the entire test. In the current study, reliability for level 2 reading comprehension was relatively high $(\alpha=.77)$. Cronbach's $\alpha$ in the current study was .83 .

\section{Reading self-concept (RSC)}

To assess RSC, the competence subscale of the Reading Self-Concept Scale (Chapman \& Tunmer, 1995) was employed. The competence subscale contains ten items (e.g., "Can you work out what a story means?"). It was administered in a classroom setting, in which the experimenter read each item aloud and participants were instructed to respond on a scale of 1 (no, never) to 5 (yes, always). Children were encouraged to request assistance if they found items difficult to understand. In most cases, help was not needed. In the current study, item 6 ("Are you good at correcting mistakes in reading?”) was removed due to a low reliability score. Cronbach's $\alpha$ for the remaining nine items was .84 .

\section{Cognitive measures}

The three cognitive measures employed in the study were as follows:

1. Nonverbal ability. A colored version of Raven's Standard Progressive Matrices was used to measure nonverbal ability (Raven, Raven, \& Court, 1998, sets A, B, and AB). Participants were instructed to select the correct missing part of a presented pattern in 36 trials of increasing difficulty. The raw scores were converted to standardized scores $(M=100, S D=15)$. Split-half internal consistency coefficients reported in the literature for the test exceed .90 (Raven, Raven, \& Court, 1998).

2. Verbal ability. The Hebrew version of the vocabulary subtest from WISC-R95 (Cahan, 1998) was used as a measure of verbal ability. This test consisted of 25 lexical items, which participants were asked to define, explain, or describe. Raw scores were transformed into standardized scores $(M=10, S D=3)$. Internal consistency of .96 and test-retest stability of .90 have been reported for the test (Cahan, 1998).

3. Rapid Automatized Naming (RAN). The letter naming task (RAN-L) was taken from Alef Ad Taf (Shany et al., 2006). The subtest consisted of five Hebrew letters: $\mathrm{D}(\mathrm{s}), \boldsymbol{K}(\mathrm{a}), \mathrm{T}(\mathrm{d}), \boldsymbol{\lambda}(\mathrm{g})$, and $\mathrm{\zeta}(\mathrm{l})$, each repeated randomly ten times. In the scoring phase, the number of letters per minute (LPM) was calculated. Reliability measures were based on correlations with a parallel test (RANNumbers) in each grade. Correlations were $r=.74$ in second grade and $r=.69$ in fourth grade. 


\section{Test points and analyses plan}

Intervention effects on reading skills and reading self-concept were longitudinally analyzed according to data collected at three test points: pretest, posttest, and follow-up. Pretest measuring took place during the first 2 months of the year. In the pretest, children were administered three reading measures (i.e., word identification, oral text reading, and reading comprehension), three cognitive measures (RAN-L, verbal, and non-verbal ability), and the RSC scale. Posttest data were gathered during the last 2 months of the year, in which children were administered three reading measures and the RSC scale. The follow-up test point was administered during November-December of the following school year. It consisted of three reading measures and the RSC scale.

Data analyses focused on comparisons among reader groups and reading conditions at the different test points. A series of two-way repeated measures ANOVAs were performed in order to examine the short-term effects of the RAP training on reading skills and RSC, comparing pre- to post-test results by reading conditions (i.e., acceleration and self-paced conditions) and reading level (i.e., typical and struggling readers). Next, ANCOVA analyses were conducted with each pretest variable serving as the covariate for the same posttest variable. These comparisons provided the statistical findings for research questions 1 and 2.

In order to examine the sustainability of improvements in reading skill and RSC (i.e., research question 3), data from the three test points were combined into a unified model using a generalized estimating equations (GEE) analysis while controlling for reading levels and experimental conditions. GEE (Liang \& Zeger, 1986) is a multilevel regression technique that adjusts standard errors to account for correlated data. The approach minimizes the accumulation of type I errors from multiple endpoint comparisons. In the GEE model, reading level and reading condition were entered as covariates. Time was categorized into two contrasts of baseline versus post-test and versus follow-up. Composite scores were calculated for each of the three test points, as follows: reading rate (word identification and oral text reading), reading accuracy (word identification and oral text reading), reading comprehension (level 1 and level 2 reading comprehension tests) ${ }^{1}$, and RSC (nine items from the RSC competence subscale).

\section{Results}

Means and standard deviations of the cognitive and reading measures are presented in Table 2. All the variables were screened for skewed measurements and kurtosis. This demonstrated that the majority of variables were normally distributed, except for word attack reading rate (skewed level $=1.2$ and kurtosis $=2.14$ ), word identification reading accuracy (skewed level $=1.22$ and kurtosis $=1.69$ ), and oral text reading accuracy (skewed level $=2.15$ and kurtosis $=5.13$ ). Due to violation of the normality assumption, these indicators were transformed using logic transformation (Armitage \& Berry, 1994), in which the logic is defined as $\ln \left(\frac{1-p}{p}\right)$, where $p$ is a proportion ${ }^{2}$.

\section{Research question 1}

\section{Can a computerized reading training program facilitate RSC?}

The two-way ANOVA results (Table 3 ) yielded a significant time effect across measures (reading rate, $F_{(1,128)}=172.46, p<.001, \eta^{2}=.59$; reading accuracy, $F_{(1,128)}=47.57, p<.001$, 
Table 2 The baseline descriptive statistics for the entire sample, in raw scores (pretest)

\begin{tabular}{|c|c|c|c|c|c|c|}
\hline & Mean & SD & Min & Max & Skewness & Kurtosis \\
\hline RAN-letters (LPM) & 40.35 & 8.49 & 21 & 76 & -0.72 & 1.37 \\
\hline Raven Standard Progressive Matrices & 26.95 & 5.28 & 13 & 36 & -0.05 & -0.36 \\
\hline WISC-R95 ${ }^{\text {a }}$ vocabulary subtest & 20.17 & 5.91 & 8 & 34 & -0.39 & -0.69 \\
\hline Word identification-reading rate (WPM) & 32.45 & 12.77 & 12.95 & 78.62 & 0.88 & 0.73 \\
\hline Word identification-reading accuracy (\% err) & 19.9 & 13.9 & 0 & 71.05 & 1.22 & 1.69 \\
\hline Word attack—reading rate (WPM) & 19.64 & 5.7 & 9 & 41.2 & 1.2 & 2.14 \\
\hline Word attack-reading accuracy (\% err) & 38.5 & 22.39 & 3.03 & 100 & 0.40 & -0.44 \\
\hline Oral text reading_reading rate (WPM) & 73.34 & 30.4 & 17 & 152 & 0.40 & -0.44 \\
\hline Oral text reading—reading accuracy (\% err) & 6.42 & 7.08 & 0 & 38.4 & 2.15 & 5.13 \\
\hline Level 1 reading comprehension ${ }^{\mathrm{b}}$ & 73.64 & 19.55 & 12.5 & 100 & -0.85 & 0.86 \\
\hline Level 2 reading comprehension ${ }^{b}$ & 39 & 31.8 & 0.0 & 100 & 0.44 & -0.86 \\
\hline Reading self-concept (competence subscale) ${ }^{c}$ & 3.89 & 0.67 & 2.0 & 5 & -0.56 & -0.19 \\
\hline
\end{tabular}

${ }^{a}$ Wechsler Intelligence Scale for Children-Revised (Cahan, 1998)

${ }^{b}$ Raw scores in percentages

${ }^{\mathrm{c}}$ Raw scores, 5-point Likert scale

$\eta^{2}=.28$; reading comprehension, $F_{(1,128)}=56.88, p<.001, \eta^{2}=.32$; and, RSC, $F_{(1,128)}=$ 24.07, $p<.001, \eta^{2}=.17$ ). Accordingly, the sample improved in measures of reading rate (i.e., from $M=33.08$ to $M=46.52$ ), reading accuracy (i.e., reduced the percentage of reading errors from $M=18.91$ to $M=13.53$ ), reading comprehension (from $M=57.82$ to $M=70.35$ ), and RSC $(M=3.89$ to $M=4.11)$.

The two-way ANCOVA results (Table 4) using the baseline measure of each variable as the covariate for the same posttest variable yielded a non-significant reading level effect for RSC and reading accuracy. These results suggest that when controlling for the baseline measures, both typical and struggling readers did not differ in gains on the RSC and reading accuracy indices. In contrast, a reading level effect was found for reading rate and reading comprehension. It seems that for typical readers the magnitude of improvement was larger in reading rate $\left(F_{(1,128)}=9.69, p<.01, \eta^{2}=.18\right)$ and in reading comprehension $\left(F_{(1,128)}=\right.$ $\left.4.18, p<.05, \eta^{2}=.03\right)$ in comparison to struggling readers.

Next, we compared the gains in RSC to those of a normative sample comprised of 100 second grade readers and 81 third grade readers, gathered from the same schools, who did not receive the intervention. The findings revealed that the RSC of struggling readers who completed the computerized training program was significantly higher $(M=3.84)$ than that of their age-matched peers from the normative sample $\left(M=3.62 ; t_{(108)}=1.99, p<.05\right)$.

\section{Research question 2}

Will the accelerated version of the RAP lead to greater RSC gains than the self-paced control version?

The ANCOVA results (Table 4) using the baseline measure of each variable as covariate for the same posttest variable comparing accelerated condition to self-paced control condition yielded non-significant condition effect across measures: reading rate, $F_{(1,128)}=$ 


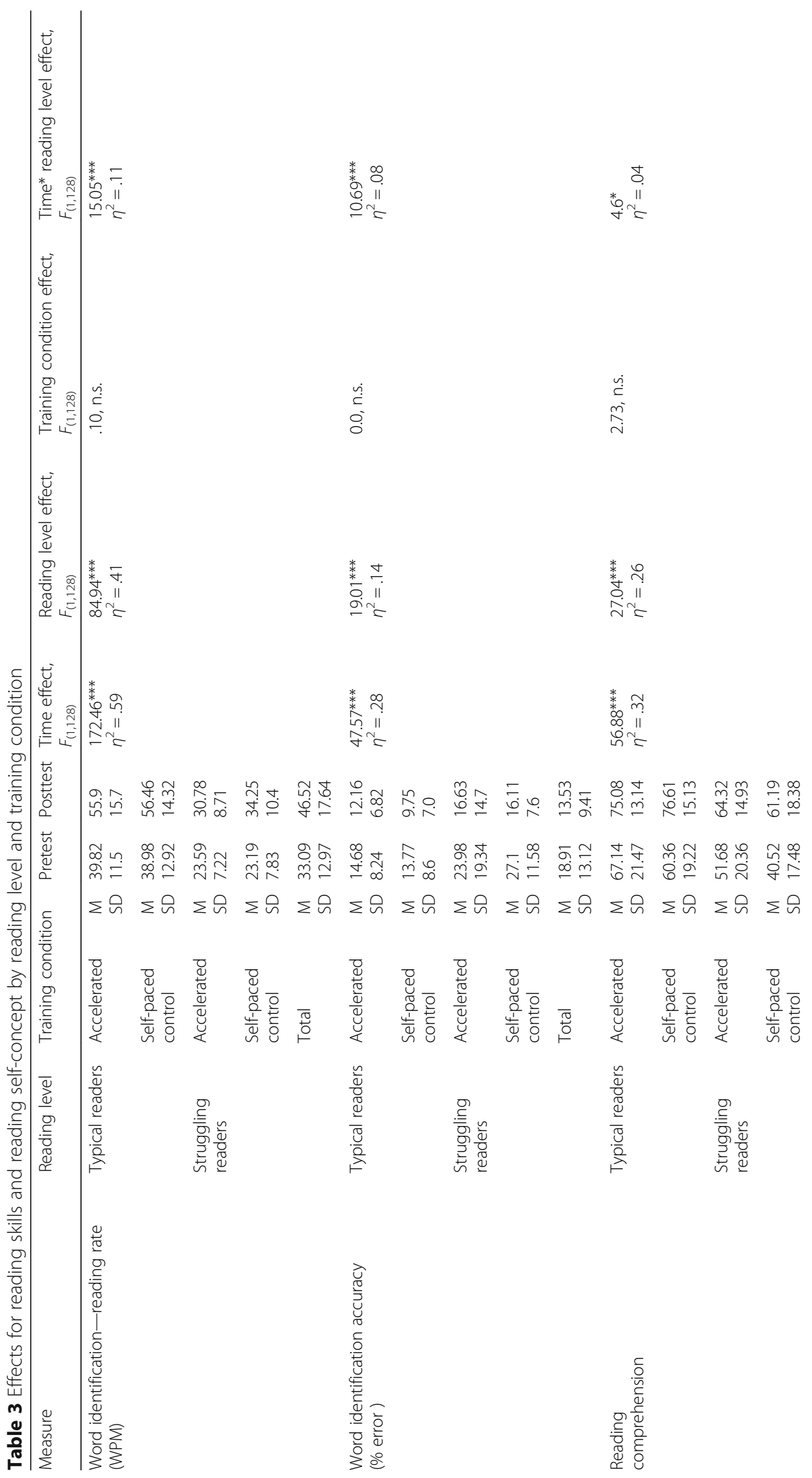




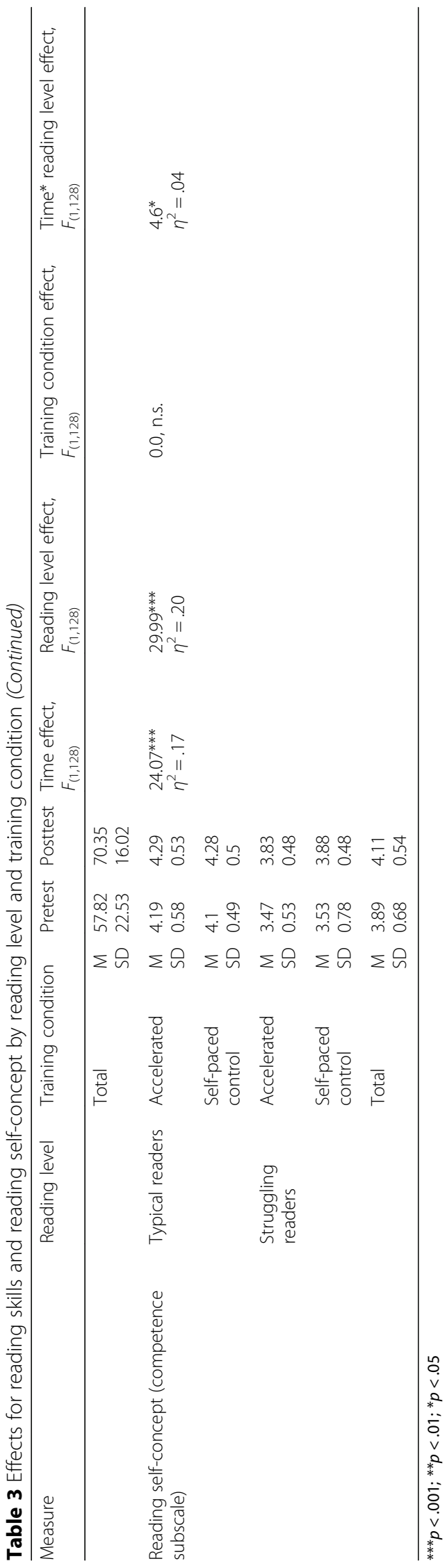


Table 4 Results of two-way ANCOVA analyses

\begin{tabular}{|c|c|c|c|c|c|}
\hline Measure & $\begin{array}{l}\text { Reading } \\
\text { level }\end{array}$ & $\begin{array}{l}\text { Training } \\
\text { condition }\end{array}$ & $\begin{array}{l}\text { Posttest adjusted means } \\
\text { and standard error }\end{array}$ & $\begin{array}{l}\text { Reading } \\
\text { level effect } \\
F_{(1,128)}\end{array}$ & $\begin{array}{l}\text { Training } \\
\text { condition } \\
\text { effect } \\
F_{(1,128)}\end{array}$ \\
\hline \multirow{4}{*}{$\begin{array}{l}\text { Word } \\
\text { identification_-reading } \\
\text { rate (WPM) }\end{array}$} & \multirow[t]{2}{*}{$\begin{array}{l}\text { Typical } \\
\text { readers }\end{array}$} & Accelerated & $47.9^{\mathrm{a}}(1.39)$ & \multirow[t]{4}{*}{$\begin{array}{l}9.69^{* *} \\
\eta^{2}=.18\end{array}$} & \multirow[t]{4}{*}{.14, n.s. } \\
\hline & & $\begin{array}{l}\text { Self-paced } \\
\text { control }\end{array}$ & $49.5^{\mathrm{a}}(2.39)$ & & \\
\hline & \multirow{2}{*}{$\begin{array}{l}\text { Struggling } \\
\text { readers }\end{array}$} & Accelerated & $39.02^{\mathrm{a}}(2.26)$ & & \\
\hline & & $\begin{array}{l}\text { Self-paced } \\
\text { control }\end{array}$ & $43.2^{\mathrm{a}}(2.12)$ & & \\
\hline \multirow{4}{*}{$\begin{array}{l}\text { Word identification } \\
\text { accuracy (\% error ( }\end{array}$} & \multirow{2}{*}{$\begin{array}{l}\text { Typical } \\
\text { readers }\end{array}$} & Accelerated & $14.15^{\mathrm{b}}(0.9)$ & \multirow[t]{4}{*}{0.0, n.s. } & \multirow[t]{4}{*}{ 3.23, n.s. } \\
\hline & & $\begin{array}{l}\text { Self-paced } \\
\text { control }\end{array}$ & $12.21^{b}(1.62)$ & & \\
\hline & \multirow{2}{*}{$\begin{array}{l}\text { Struggling } \\
\text { readers }\end{array}$} & Accelerated & $14.93^{b}(1.46)$ & & \\
\hline & & $\begin{array}{l}\text { Self-paced } \\
\text { control }\end{array}$ & $11.69^{b}(1.38)$ & & \\
\hline \multirow[t]{4}{*}{ Reading comprehension } & \multirow[t]{2}{*}{$\begin{array}{l}\text { Typical } \\
\text { readers }\end{array}$} & Accelerated & $71.84^{\mathrm{C}}(1.85)$ & \multirow[t]{4}{*}{$\begin{array}{l}4.18^{*} \\
\eta^{2}=.03\end{array}$} & \multirow[t]{4}{*}{0.22, n.s. } \\
\hline & & $\begin{array}{l}\text { Self-paced } \\
\text { control }\end{array}$ & $71.84^{\mathrm{C}}(1.85)$ & & \\
\hline & \multirow{2}{*}{$\begin{array}{l}\text { Struggling } \\
\text { readers }\end{array}$} & Accelerated & $66.76^{\mathrm{C}}(2.81)$ & & \\
\hline & & $\begin{array}{l}\text { Self-paced } \\
\text { control }\end{array}$ & $71.84^{\mathrm{C}}(1.85)$ & & \\
\hline \multirow[t]{4}{*}{ Reading self-concept } & \multirow{2}{*}{$\begin{array}{l}\text { Typical } \\
\text { readers }\end{array}$} & Accelerated & $4.12^{d}(0.58)$ & \multirow[t]{4}{*}{.58, n.s. } & \multirow[t]{4}{*}{0.11, n.s. } \\
\hline & & $\begin{array}{l}\text { Self-paced } \\
\text { control }\end{array}$ & $4.16^{d}(0.49)$ & & \\
\hline & \multirow{2}{*}{$\begin{array}{l}\text { Struggling } \\
\text { readers }\end{array}$} & Accelerated & $4.07^{d}(0.93)$ & & \\
\hline & & $\begin{array}{l}\text { Self-paced } \\
\text { control }\end{array}$ & $4.07^{d}(0.85)$ & & \\
\hline
\end{tabular}

${ }^{* *} p<.01 ;{ }^{*} p<.05$

Covariates are evaluated according to:

${ }^{\text {a }}$ Pretest word identification-reading rate $($ WPM $)=32.48$

b Pretest word identification accuracy (\% error) $=18.96$

${ }^{\mathrm{c}}$ Pretest reading comprehension $=56.7$

${ }^{\mathrm{d}}$ Pretest reading self-concept $=3.91$

0.14 , n.s.; reading accuracy, $F_{(1,128)}=3.23$, n.s.; reading comprehension, $F_{(1,128)}=0.22$, n.s.; and $\operatorname{RSC}\left(F_{(1,128)}=0.11\right.$, n.s.

\section{Research question 3}

What are the long-term effects of computerized reading training in terms of sustaining RSC gains?

The results of the GEE multilevel longitudinal model (see Tables 5 and 6) yielded significant effects of time (reading rate: $\chi^{2}(2, N=130)=888.11, p<.001$; reading accuracy: $X^{2}(2, N=130)=750.1, p<.001$; reading comprehension: $X^{2}(2, N=130)=84.28, p<.001$; RSC: $\left.\chi^{2}(2, N=130)=14.05, p<.01\right)$. Significant effects were found with respect to reading level as well (reading rate: $\chi^{2}(2, N=130)=129.66, p<.001$; reading accuracy: $\chi^{2}(2$, $N=130)=33.87, p<.001$; reading comprehension: $\chi^{2}(2, N=130)=32.76, p<0.001$; RSC: $\left.\chi^{2}(2, N=130)=20.11, p<.001\right)$. In addition, a time $\times$ reading level interaction emerged with respect to reading rate, $\chi^{2}(2, N=130)=26.96, p<.001$, meaning that 
Table 5 Multilevel model: generalized estimating equations (GEE)

\begin{tabular}{|c|c|c|c|c|c|c|}
\hline & \multirow[t]{2}{*}{ B } & \multirow[t]{2}{*}{ SE } & \multicolumn{2}{|c|}{ 95\% Wald confidence interval } & \multicolumn{2}{|l|}{ Hypothesis test } \\
\hline & & & Lower & Upper & Wald chi-square & df \\
\hline \multicolumn{7}{|l|}{ Reading self-concept } \\
\hline Intercept & 3.797 & 0.1080 & 3.585 & 4.01 & $1235.35^{* * *}$ & 1 \\
\hline Typical-struggling readers & 0.442 & 0.0986 & 0.249 & 0.635 & $20.11^{* * *}$ & 1 \\
\hline Accelerated-self-paced & -0.011 & 0.0988 & -0.205 & 0.182 & 0.013 & 1 \\
\hline Time1-time3 & -0.120 & 0.0612 & -0.240 & 0.000 & $3.815^{*}$ & 1 \\
\hline Time2-time3 & 0.101 & 0.0487 & 0.006 & 0.197 & $4.301^{*}$ & 1 \\
\hline \multicolumn{7}{|l|}{ Reading rate (words + text) } \\
\hline Intercept & 63.509 & 2.10 & 59.39 & 67.63 & $911.5^{* * *}$ & 1 \\
\hline Typical-struggling readers & 26.283 & 2.31 & 21.76 & 30.81 & $129.66^{* * *}$ & 1 \\
\hline Accelerated-self-paced & -1.846 & 2.44 & -6.62 & 2.93 & 0.574 & 1 \\
\hline Time1-time3 & -36.282 & 1.28 & -38.80 & -33.76 & $797.99^{* * *}$ & 1 \\
\hline Time2-time3 & -6.422 & 0.98 & -8.36 & -4.49 & $42.31^{* * *}$ & 1 \\
\hline \multicolumn{7}{|c|}{ Reading accuracy (words + text) ${ }^{a}$} \\
\hline Intercept & -2.272 & 0.15 & -2.57 & -1.97 & $219.36^{* * *}$ & 1 \\
\hline Typical-struggling readers & -1.084 & 0.019 & -1.449 & -0.72 & $33.87^{* * *}$ & 1 \\
\hline Accelerated-self-paced & -0.15 & 0.19 & -0.52 & 0.22 & 0.625 & 1 \\
\hline Time1-time3 & 1.13 & 0.08 & 0.972 & 1.287 & $191.51^{* * *}$ & 1 \\
\hline Time2-time3 & 0.793 & 0.03 & 0.736 & 0.851 & $726.04^{* * *}$ & 1 \\
\hline \multicolumn{7}{|l|}{ Reading comprehension ${ }^{a}$} \\
\hline Intercept & 1.009 & 0.29 & 0.441 & 1.577 & $12.12^{* * *}$ & 1 \\
\hline Typical-struggling readers & 1.735 & 0.30 & 1.14 & 2.33 & $32.76^{* * *}$ & 1 \\
\hline Accelerated-self-paced & 0.39 & 0.31 & -0.225 & 1.008 & 1.54 & 1 \\
\hline Time1-time3 & -1.97 & 0.214 & -2.39 & -1.55 & $84.26^{* * *}$ & 1 \\
\hline Time2-time3 & -0.552 & 0.1801 & -0.905 & -0.199 & $9.40^{* *}$ & 1 \\
\hline
\end{tabular}

typical readers improved their reading rate more profoundly than struggling readers. However, no significant effects of reading condition were found, suggesting that the training conditions did not differ from one another in terms of the sustainability of either reading measures or RSC. Fisher's LSD analyses demonstrated significant differences between the follow-up and baseline time points across all measures.

\section{Discussion}

A growing body of research suggests that the relationship between academic achievements and social-emotional factors is dynamic and reciprocal (Seaton, Parker, Marsh, Craven, \& Yeung, 2013). In light of the growing use of technology in the classroom, this study wished to investigate whether computer-based training could facilitate both the student's academic factors and his social-emotional ones.

The results found add to the literature a causative and dynamic model of achievement and self-perception in reading. The current research findings support a direct link between reading training and RSC and demonstrate that by training reading using a computer-based program adapted to the reader's level and pace, it is possible to obtain gains in RSC. RSC gains following reading intervention were also found in previous 
Table 6 Reading self-concept, reading rate, reading accuracy, and reading comprehension effects across time

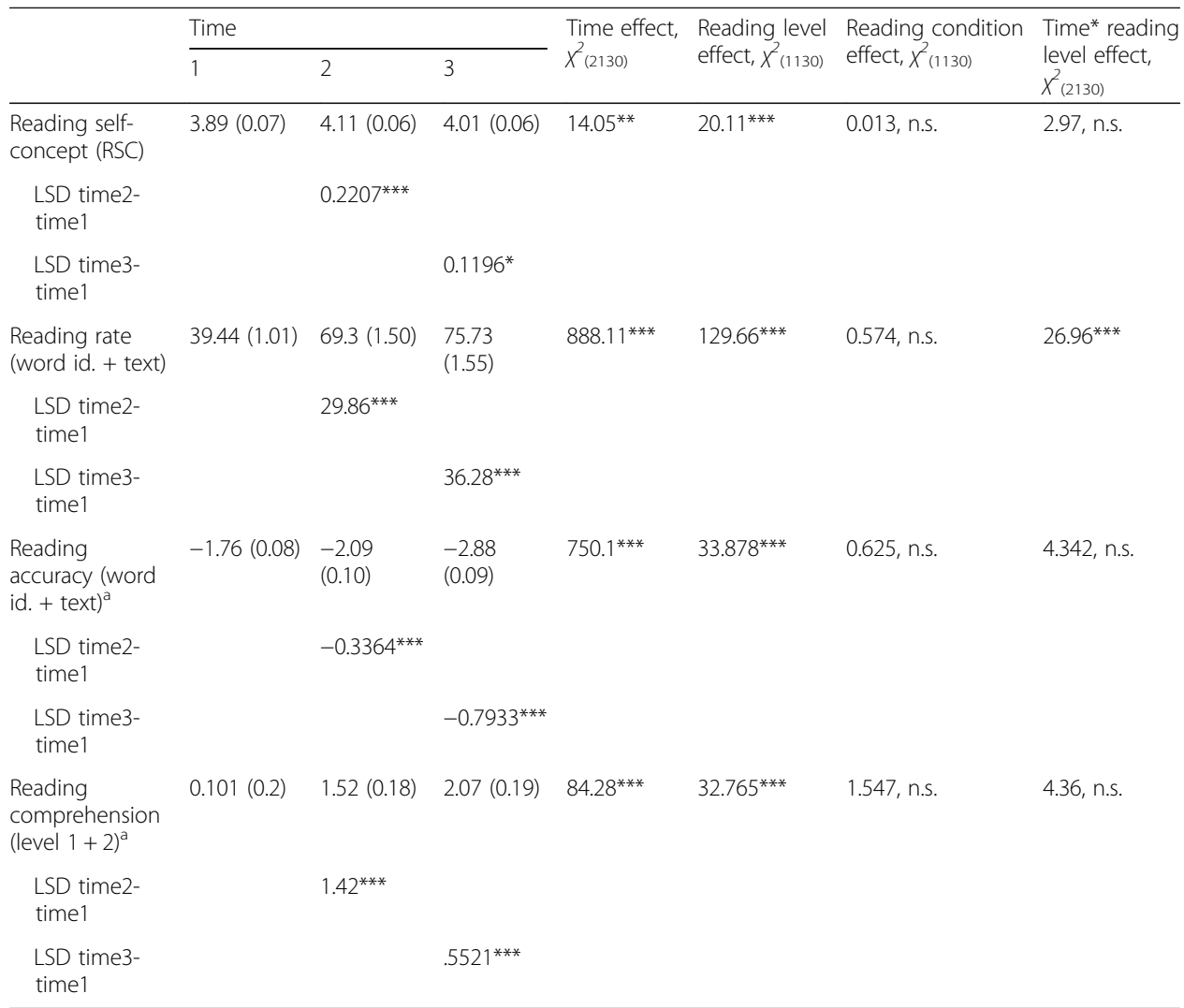

Numbers in parenthesis represent standard error

Word id. word identification

${ }^{*} p<.05 .{ }^{* *} p<.01 .{ }^{* * *} p<.001$.

a Values in logit transformation: $\ln \left(\frac{1-p}{p}\right)$

studies, such as that conducted by Higgins, Fitzgerald, and Howard (2015). They suggested that a reading training program which provides an errorless learning experience, using tasks on increasing difficulty levels based on the student's individual ability, can facilitate improvement in reading as well as positive feelings towards reading. While typical and struggling readers significantly improved their reading skills and RSC, time $x$ reading level interactions emerged across measures. These interactions suggest that the magnitude of improvement in three out of four measures, including RSC, was much larger for struggling readers. Furthermore, the RSC of struggling readers who completed the computerized training program was significantly higher than the RSC of those from a normative sample who did not receive the intervention program. These findings suggest that reading training that gives struggling readers a sense of proficiency and improvement could encourage them to reevaluate their reading skills and ability to succeed in reading tasks and, as a result, aid in forming a more positive RSC.

In contradiction to the hypothesis, participants from both reading conditions showed similar significant improvements in reading and in RSC. Therefore, the significant change in RSC cannot be attributed to the acceleration component of the software. The question remains as to what caused the change in RSC.

One possible explanation is that the software offered closed and highly structured reading units designed to promote lower-level reading skills. All participants were 
required to complete the same amount of items, whether it took them 20 or $30 \mathrm{~min}$ (gains in RSC were not influenced by time spent on the task, $t_{(128)}=-1.36, \mathrm{n} . \mathrm{s}$ ). This framework helped maintain a consistently high quality of training, which was less dependent on teacher expertise or student motivation to read than most interventions.

Furthermore, the RAP enabled participants to read independently by using age-appropriate reading materials and by adjusting reading rate to match each participant's ability, thus allowing for a nourishing individual environment in which children could advance according to their ability and at their own pace (Bandura, 1993; Cheung \& Slavin, 2013; Van Daal \& Reitsma, 2000).

Gains following a training program are commonly found right after the training ends, as seen in this study as well. But, from a pedagogical point of view, it was important to test the long-term effects of reading training on gains in RSC, as these have rarely been studied and are extremely important for instruction and intervention purposes. The finding that RSC was significantly higher 6 months after training ended than it was at the baseline measure is compatible with the conclusions of a previous meta-analysis of global self-concept intervention studies (Haney \& Durlak, 1998) and a more recent meta-analysis of academic and non-academic self-concept interventions (O'Mara, Marsh, Craven, \& Debus, 2006). The fact that reading skill improvements did not stop when the intervention was completed, but rather continued between post-test and follow-up, likely caused a sustaining of the internal sense of improvement in reading. In this sense, it is plausible that ongoing improvements in reading led to a pattern of success, which contributed to the maintenance of gains in RSC over time.

Although RSC levels in the follow-up test point were higher than those found in the pretest, they were not as high as the RSC levels noted on the posttest checkpoint. This finding is consistent with previous studies (Grossman \& Rhodes, 2002; Hattie, 1992). In those studies, a decrease in RSC was also observed between posttest and follow-up. This decrease may reflect more accurately the overall improvement in RSC, because it is less influenced by different types of bias that sometimes emerge after completing interventions (i.e., euphoria or Hawthorne effect) and tend to dissolve over time (Harter, 2012; Marsh, 1986), leading to a decrease between posttest and follow-up.

\section{Limitations of the study and future directions}

This study has several limitations that concern participants' socioeconomic background, age, and orthography. Although the sample was comprised of students from three diverse schools, two of which were public schools, further studies should account for socioeconomic background, while checking for differences in reading and RSC gains between students at different socioeconomic levels. Furthermore, it would be interesting to examine whether the results can be replicated in other orthographies, with a larger sample. Another possible line of research could use longitudinal and cross-sectional studies in order to examine the relationship between speed-related reading components and RSC among older participants as well, since this study addressed only second and third grade students.

For ethical reasons, this study did not include a group of children who received no treatment at all. First, the issue of including a no-treatment control group in educational studies has been discussed (Therrien, Kirk, \& Woods-Groves, 2012), 
and due to the length of the treatment in this study, a waiting list could not be included. In addition, the positive influence of reading training is not necessarily straightforward, and it may sometimes lead to less desirable consequences in terms of RSC, simply because readers are confronted with their reading deficiency (Chapman, Tunmer, \& Prochnow, 2001; Chen \& Savage, 2014; Förster \& Souvignier, 2014). In order to address the question of treatment outcomes, at the end of the program, we compared the posttest results to those of a normative sample of children. Our finding that the RSC of struggling readers who completed the computerized training program was significantly higher than the RSC of those from a normative sample strengthens the notion that the treatment led to positive outcomes for this population.

\section{Endnotes}

${ }^{1}$ Composite scores for reading accuracy and reading comprehension were transformed using logit transformation.

${ }^{2}$ Armitage and Berry (1994) present log transformation as an appropriate solution for converting a positive skew distribution to a normal distribution because it compresses the tails of the distribution by reducing the relative spacing of scores on the right side of the distribution.

\section{Abbreviations \\ GEE: Generalized estimating equations; RAN-L: Rapid automatized naming of letters; RAP: Reading acceleration program; RSC: Reading self-concept}

Acknowledgements

Not applicable.

Funding

Not applicable.

Availability of data and materials

Not applicable.

Authors' contributions

All authors read and approved the final manuscript.

Authors' information

Not applicable.

Competing interests

The authors declare that they have no competing interests.

\section{Publisher's Note}

Springer Nature remains neutral with regard to jurisdictional claims in published maps and institutional affiliations.

\section{Author details}

${ }^{1}$ Department of Learning Disabilities and Special Education, University of Haifa, 31905 Mount Carmel, Israel. ${ }^{2}$ Shaanan Academic Religious Teachers' College, Haifa, Israel. ${ }^{3}$ Gordon College of Education, Haifa, Israel.

Received: 20 November 2018 Accepted: 23 April 2019

Published online: 11 June 2019

\section{References}

Armitage, P., \& Berry, G. (1994). Statistical methods in medical research (3rd ed.). Oxford: Blackwell Science.

Bandura, A. (1986). Social foundations of thought and action: A social cognitive theory, Prentice-Hall, Englewood Cliffs, NJ.

Bandura, A. (1993). Perceived self-efficacy in cognitive development and functioning. Educational Psychologist, 28(2), $117-148$.

Bates, C. C., D'Agostino, J. V., Gambrell, L., \& Xu, M. (2016). Reading recovery: Exploring the effects on first-graders' reading motivation and achievement. Journal of Education for Students Placed at Risk (JESPAR), 21(1), 47-59.

Berninger, V. W., Lee, Y.L., Abbott, R.D., \& Breznitz, Z. (2009). Lessons in monitoring response to intervention in Sequoyah Reading-Writers Workshop for students with Dyslexia. Annals of Dyslexia, (special issue on writing). 
Berninger, V. W., Lee, Y. L., Abbott, R. D., \& Breznitz, Z. (2013). Teaching children with dyslexia to spell in a reading-writers' workshop. Annals of Dyslexia, 63(1), 1-24.

Brande, S. (2011). The Effect of Reading Acceleration Training on the Reading Ability of Young Dyslexics as Compared with Regular Readers. (Doctoral dissertation, University of Haifa, in Hebrew).

Breznitz, Z. (1997). Effects of accelerated reading rate on memory for text among dyslexic readers. Journal of Educational Psychology, 89, 289-308.

Breznitz, Z. (2006). Fluency in reading: Synchronization of processes. Mahwah, NJ: Lawrence Erlbaum.

Breznitz, Z., \& Share, D.L. (1992). The effect of accelerated reading rate on memory for text. Journal of Educational Psychology, 84, 193-199.

Breznitz, Z., Shaul, S., Horowitz-Kraus, T., Sela, I., Nevat, M., \& Karni, A. (2013). Enhanced reading by training with imposed time constraint in typical and dyslexic adults. Nature communications, 4, 1486.

Cahan, S. (1998). Intelligence scale for children. Revised Manual. Hebrew version of Wechsler's 1974 version. Jerusalem: Psychoeducational Services and H. Szold Institute.

Chapman, J. W., \& Tunmer, W. E. (1995). Development of young children's reading self concepts: An examination of emerging subcomponents and their relationship with reading achievement. Journal of Educational Psychology, $87(1), 154-167$.

Chapman, J. W., \& Tunmer, W. E. (1997). A longitudinal study of beginning reading achievement and reading self-concept. British Journal of Educational Psychology, 67, 279-291.

Chapman, J. W., \& Tunmer, W. E. (2003). Reading difficulties, reading-related self-perceptions, and strategies for overcoming negative self-beliefs. Reading and Writing Quarterly, 19, 5-24.

Chapman, J. W., Tunmer, W. E., \& Prochnow, J. E. (2001). Does success in the Reading Recovery program depend on developing proficiency in phonological-processing skills? A longitudinal study in a whole language instructional context. Scientific Studies of Reading, 5(2), 141-176.

Chen, V., \& Savage, R. S. (2014). Evidence for a simplicity principle: Teaching common complex grapheme-to-phonemes improves reading and motivation in at-risk readers. Journal of Research in Reading, 37(2), 196-214.

Conlon, E. G., Zimmer-Gembeck, M. J., Creed, P. A., \& Tucker, M. (2006). Family history, self perceptions, attitudes and cognitive abilities are associated with early adolescent reading skills. Journal of Research in Reading, 29(1), 11-32.

Conradi, K., Jang, B. G., \& McKenna, M. C. (2014). Motivation terminology in reading research: A conceptual review. Educational Psychology Review, 26(1), 127-164.

Förster, N., \& Souvignier, E. (2014). Learning progress assessment and goal setting: Effects on reading achievement, reading motivation and reading self-concept. Learning and Instruction, 32, 91-100.

Grossman, J. B., \& Rhodes, J. E. (2002). The test of time: Predictors and effects of duration in youth mentoring relationships. American Journal of Community Psychology, 30(2), 199-219.

Guthrie, J. T., \& Klauda, S. L. (2014). Effects of classroom practices on reading comprehension, engagement, and motivations for adolescents. Reading Research Quarterly, 49(4), 387-416.

Haney, P., \& Durlak, J. A. (1998). Changing self-esteem in children and adolescents: A meta-analytical review. Journal of Clinical Child Psychology, 27(4), 423-433.

Harter, S. (2012). The construction of the self: Developmental and sociocultural foundations. New York: Guilford Press.

Hattie, J. A. (1992). Self-concept. Hillsdale, NJ: Lawrence Erlbaum Associates, Inc.

Heath, N. L., \& Ross, S. (2000). Prevalence and expression of depressive symptomatology in students with and without learning disabilities. Learning Disability Quarterly, 23, 24-36.

Higgins, E., Fitzgerald, J., \& Howard, S. (2015). "Literacy Lift-Off": An experimental evaluation of a reading recovery programme on literacy skills and reading self-concept. Educational Psychology in Practice, 31(3), 247-264.

Hornery, S., Seaton, M., Tracey, D., Craven, R. G., \& Yeung, A. S. (2014). Enhancing reading skills and reading self-concept of children with reading difficulties: Adopting a dual approach intervention. Australian Journal of Educational \& Developmental Psychology, 14, 131-143.

Horowitz-Kraus, T., Cicchino, N., Amiel, M., Holland, S. K., \& Breznitz, Z. (2014). Reading improvement in English-and Hebrewspeaking children with reading difficulties after reading acceleration training. Annals of Dyslexia, 64(3), 183-201.

Hurry, J., \& Sylva, K. (2007). Long-term outcomes of early reading intervention. Journal of Research in Reading, 30(3), 227-248.

Jenkins, J. R., Fuchs, L. S., Van Den Broek, P., Espin, C., \& Deno, S. L. (2003). Sources of individual differences in reading comprehension and reading fluency. Journal of Educational Psychology, 95(4), 719.

Kasperski, R., Shany, M., \& Katzir, T. (2016). The role of RAN and reading rate in predicting reading self-concept. Reading and Writing, 29(1), 117-136.

Katzir T., Hershko, S., \& Halamish, V. (2013) The effect of font size on reading comprehension on second and fifth grade children: Bigger is not always better. http://www.plosone.org/article/info:doi/10.1371/journal.pone.0074061

Katzir, T., Lesaux, N. K., \& Kim, Y. S. (2009). The role of reading self-concept and home literacy environment in fourth grade reading comprehension. Journal of Reading and Writing, 22(3), 261-276.

Klassen, R., Tze, V., \& Hannock, W. (2011). Internalizing problems of adults with learning disabilities: A meta-analysis. Journal of Learning Disabilities, 46, 317-327.

Law, M., \& Kratochwill, T. R. (1993). Paired reading: An evaluation of a parent tutorial program. School Psychology International, 14, 119-147.

Liang, K. Y., \& Zeger, S. L. (1986). Longitudinal data analysis using generalized linear models. Biometrika, 7, 13-22.

Marsh, H. W. (1986). Verbal and math self-concepts: An internal/external frame of reference model. American Educational Research Journal, 23(1), 129-149.

Nagler, T., Korinth, S. P., Linkersdörfer, J., Lonnemann, J., Rump, B., Hasselhorn, M., \& Lindberg, S. (2015). Text-fading based training leads to transfer effects on children's sentence reading fluency. Frontiers in Psychology, 6.

Nes Ferrara, S. L. (2005). Reading fluency and self-efficacy: A case study. International Journal of Disability, Development, and Education, 52, 215-231.

Nevo, E., Brande, S., \& Shaul, S. (2016). The effects of two different reading acceleration training programs on improving reading skills of second graders. Reading Psychology, 37(4), 533-546.

O'Mara, A. J., Marsh, H. W., Craven, R. G., \& Debus, R. L. (2006). Do self-concept interventions make a difference? A synergistic blend of construct validation and meta-analysis. Educational Psychologist, 41(3), 181-206. 
Raven, J., Raven, J.C., \& Court, J.H. (1998). Raven manual, section 1, general overview, 1998 edition. Oxford, UK: Oxford Psychologists Press.

Seaton, M., Parker, P., Marsh, H. W., Craven, R. G., \& Yeung, A. S. (2014). The reciprocal relations between self-concept, motivation and achievement: Juxtaposing academic self-concept and achievement goal orientations for mathematics success. Educational Psychology, 34(1), 49-72.

Shany, M., Lahman, D., Shalem, T., Bahat, A., \& Zeiger, T. (2006). "Alef ad taf" - a system for diagnosing disabilities in the processes of reading and writing according to national norms. Holon: Yesod publishing.

Snellings, P., van der Leij, A., de Jong, P. F., \& Blok, H. (2009). Enhancing the reading fluency and comprehension of children with reading disabilities in an orthographically transparent language. Journal of Learning disabilities, 42(4), 291-305.

Stanovich, K. E. (2009). Matthew effects in reading: Some consequences of individual differences in the acquisition of literacy. Journal of Education, 189(1-2), 23-55.

Therrien, W. J., Kirk, J. F., \& Woods-Groves, S. (2012). Comparison of a reading fluency intervention with and without passage repetition on reading achievement. Remedial and Special Education, 33(5), 309-319.

Torgesen, J. K., Alexander, A. W., Wagner, R. K., Rashotte, C. A., Voeller, K. K., \& Conway, T. (2001). Intensive remedial instruction for children with severe reading disabilities immediate and long-term outcomes from two instructional approaches. Journal of Learning Disabilities, 34(1), 33-58.

Tov-li, E. (2000). A reading and writing test battery for 1st - 9th graders (in Hebrew). Kiriat Bialik: Ach.

Van Daal, V., \& Reitsma, P. (2000). Computer-assisted learning to read and spell: Results from two pilot studies. Journal of Research in Reading, 23(2), 181-193.

Zimmerman, B. J. (2002). Becoming a self-regulated learner: An overview. Theory Into Practice, 41(2), 64-70.

\section{Submit your manuscript to a SpringerOpen ${ }^{\circ}$} journal and benefit from:

- Convenient online submission

- Rigorous peer review

- Open access: articles freely available online

High visibility within the field

- Retaining the copyright to your article

Submit your next manuscript at $\boldsymbol{\nabla}$ springeropen.com 